\title{
Building A LEgal EXPERT SySTEM For LEgaL REASONING IN SPECIFIC DOMAIN-A SURVEY
}

\author{
Venkateswarlu Naik.M $^{1}$ and Sushant Lokhanday ${ }^{2}$ \\ ${ }^{1}$ Department of Computer Science, Keshava Memorial Institute of Technology, \\ Hyderabad, India \\ vvnaikcse@gmail.com \\ ${ }^{2}$ Department of Computer Science, Keshava Memorial Institute of Technology, \\ Hyderabad, India \\ sushaant@gmail.com
}

\begin{abstract}
There is an urgent need to develop a legal expert system for the people to solve their legal troubles in order reduce problems to the people for frequently arising legal solutions or legal queries, there is a need of legal lawyer is mandatory, so there is an urgent need for the use of practical AI solutions in many of areas for problems which people encounter in their daily lives. In this context building a legal expert system for the people is most adequate to make legal decisions in a particular domain through which people can get basic service or suggestions or counseling or Fact finding and diagnosing few things associated to their domain. Such kind of emerging domain is called Immovable Property Acquisition (IMP) like Tangible properties Land, House etc.., In order to build such kind of systems certain prior domain knowledge must be acquired. The main fundamental goal of this paper is to survey distinguish prerequisites information about to make legal expert system. Here primarily focusing regarding Traditional model of legal reasoning, proposed approach by Expert System, Various Logical components, Types of Legal Inference Techniques to automate the legal tasks.
\end{abstract}

\section{KEYWORDS}

Legal Reasoning, Legal Expert System, Immovable Property Acquisition, Legal domain reasoning approaches, Expert System Inference Methods, Various Expert systems in different domains, Knowledge Base, Inference Engine

\section{INTRODUCTION}

In artificial intelligence, an expert system is computer systems that emulate the decision-making ability of a human expert [1]. Usually Expert systems are building to resolve compound problems by conducting reasoning regarding knowledge, resembling an expert. The primary expert systems were designed in the 1970s and then reproduced in the 1980s [2]. The first victorious software in Artificial Intelligence is Expert systems [3]. Basically Computer-based Expert systems has been building in order to behave like a human expert appropriate field. Expert system contains knowledge acquired from the human experts, which is equivalent to a database but it is having set of predefined rules that may be make use of to solving a particular problem. A user interface of expert system provides an environment which allows the user to respond answers to questions posed by the system. Currently most familiar used expert systems are in the following domains such as medicine, mechanical, reasoning and education etc.... Usually Expert system also known as KBS (Knowledge Based System). Expert system defined as "a program that consist 
knowledge, inference rules to resolve problems which is adequate appropriate human expertise knowledge for associate solutions" [4]. An expert system is an intelligent system that is able to use expert knowledge, stored in the form of inference procedures to resolve complex problems'. Most of these systems use a set of if/then type rules and an inference engine. Examples of expert systems are numerous including the familiar early application MYCIN Expert System designed to assist medical diagnosis. Apart from following are the various expert systems in distinguish domains listed in Table1.

There are mainly four important key terms involved in building an expert system they are Knowledge Base, Inference Engine, User Interface, and Knowledge Engineering. Following Figure1 gives an idea about relations between each component.

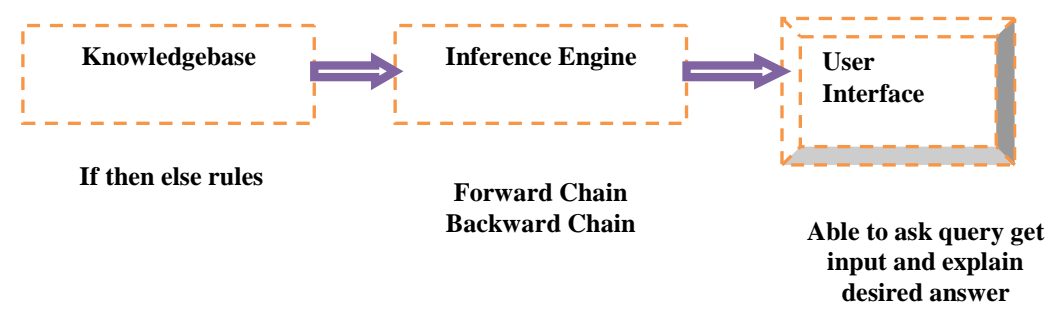

Figure 1. Expert System Functional Scenario

"Knowledge Base" is the one of the module of expert system, which consist information provided by the expert. Acquired information from expert must be in the form of problem solving rules or procedures. The knowledge acquired from the expert must be encoded by certain methods which are understandable by the expert system. Most familiar methods are IF THEN Rules, Semantic Networks, Frames.

Example: Rules "IF THEN" Rules are form of encoding knowledge in expert system. Knowledge Base Set Rules:

$$
\begin{array}{cc}
\text { Rule1: if } \mathrm{P} \text { and } \mathrm{R} & \text { Then } \mathrm{T} \\
\text { Rule2: if } \mathrm{P} \text { and } \mathrm{S} & \text { Then } \mathrm{U} \\
\text { Rule3: if } \mathrm{Q} \text { and } \mathrm{W} & \text { Then X } \\
\text { Problem: If } \mathrm{P} \text { and } \mathrm{Q} \text { is True } & \text { Then X is True }
\end{array}
$$

"Inference Engine" is broad control module for plot a route and understanding knowledge and obtained the result in a organized manner. It applies the self evident knowledge on knowledge base with concern data for certain desired result. This component follows either of one inference techniques Forward Chain or Backward Chain. Forward Chain is the method for performing inferences on rule base. This Technique is also called as Data Driven or Top down Method. This method compares the data with IF condition rules and determines which rule to be invoking in order to reach expected goal. Backward chain method is called as "Goal Driven or Bottom to Top method". This method checking for action in the THEN statement rules that matches the desired goal.

"User Interface" provides an environment where it is permit the user to obtain reasonable result by responding to questions posed by the system. This module contains Scrolling dialog interfaces, popup menus, windows, special interfaces, some tools which require interacting with the user. 
International Journal of Computer Science \& Information Technology (IJCSIT) Vol 4, No 5, October 2012

"Knowledge Engineering" is a discipline that involves integrating knowledge into computer systems in order to solve complex problems normally requiring a high level of human expertise [5].

\subsection{Problem Statement}

A brief Survey of Research Work on Legal Reasoning Expert Systems in legal domain.

\subsection{Intention}

The key purpose of this study is a concise survey of the research work done by the earlier researchers in the area of Legal domain to make legal expert system. Although this study has been covers the essential information which requires building a model of legal expert system in desired area.

\subsection{Significance of Study}

It is very cumbersome to build an expert system which is having ability to reproduction of logical decision making process of human expert. To perform Legal reasoning needs understanding, analyze certain legal case rules which are possible to build a computer logic which appears to replicate aspects of this process. Consequently authors of this paper come to a decision to know how far research works done on this area of Legal expert system over past decade. Therefore this survey work aids the authors in their research direction to enhance novel paradigms of Legal expert systems.

\subsection{Structure of Paper}

This paper primarily analyzing essential back ground information in order to build legal advisory expert system. Section 2 summarizes fundamental motivations to apply expert system techniques to build Legal Expert System. Section3 expressing briefly about most important legal terminologies such as Case, Statute etc.., to process legal reasoning.Section4 describes regarding literature study in concise manner. Apart from section5 summarizes about conclusion and future enhancement of this research work. Lastly about references utilized in this entire paper.

\section{Reasons To Apply Expert System Techniques To Build Legal REASONING}

Following are the some important features to applying expert system techniques to building Legal Expert System.

High Performance - The system must be capable to responding at the level of equal to human expert in a specific field. That is the equality of advice given by the system must have high integrity.

Quick response time - The system takes reasonable time comparatively human expert to reach decision. Sometime in case of emergency may require response faster than human, in this case real-time expert system is a good choice.

Good Reliability - The expert system always reliable if the expert system programmed accurately until and unless mistake made by the expert, which may happen if the human expert is tired or stress. 
Reduced Cost - The cost of providing expertise per a user is greatly lowered.

Reduced Danger - The expert systems can be used in locations that might be harmful for a human.

Permanence - Expert system is permanent. But human experts, who may retire, quit, die.

Multiple Expertise - This feature allows extracting the knowledge from distinguish experts to solve complex troubles by conducting reasoning with the help of expert system.

Explanation - Expert system shows the detailed arguments how the reasoning takes place to determine appropriate conclusion.

Steady, Unemotional - This feature is mandatory in some tragedy circumstances where human expert unable to gives the solutions due to exhaustion.

Intelligence Database - Expert Systems are making use of like a intelligence database at time when all adequate rules deposited in this system. Like Data Mining Techniques.

\section{Back Ground Legal KnOWLedge}

Legal reasoning usually a process of consider a particular situation, extracting which part of the law rules belonging to that condition. Subsequently relate the rules regarding associated law to the corresponding situation and resolve what the outcome conclusion is. Many lawyers still taking legal decisions by following olden reasoning methods such as inductive and deductive methods. At this movement getting conclusion with the help of legal expert system is most adequate.

All legal reasoning follows one path. Following are the most adequate factors in order to take legal decisions.

- Issue

- Issue is sets up the problem. It deals about what specifically is being debated. To identify the law issue it is necessary to understand (i) know the facts of the case (ii) understand a law well enough to recognize when it may have been violated

- Rule

- The Rule is extracted from the law that can be recognized in Issue step. Along with this necessary to acquire quotation of the rule from suitable primary source. Here only name of the rule is not sufficient rather than that gather summary statement because these words of the rules would be compared to the facts. Although words of the rules also provide the information needed for the conclusion step. Although even rules are not formed properly corresponding analysis will be imperfect.

- Fact

- The Fact of the case expresses what happened to cause the dispute. In generally facts emphasizes behavior of the person about a situation. And subsequently fact may express about when and where the situation happened, status at the time the behavior happened. Apart from this it includes affected things, and how the things were changed and etc...?

- Analysis

○ During Analysis step performing comparison between Rules (the words of rules 
International Journal of Computer Science \& Information Technology (IJCSIT) Vol 4, No 5, October 2012

- Describe the conduct that prohibits or requires or permits) and Facts (the words of

the facts describe the conduct that occurred) in order to ascertain whether the two

sets of words describes the same conduct.

a) Identify one rule from available ones

b) Use one legal reasoning method such as Inference methods to compare rule to the facts and determine whether the rule is satisfied.

c) Repeat step a, b for each rule

- Conclusion

- For every rule, along with describing certain conduct, also gives conclusion to be reached when that conduct occurs. This process done with the help of IF then Rules.

a) IF the conduct described the rule occurred

b) THEN the outcome result acknowledged in the rule must be followed.

- After the analysis done by comparison it is make available respective data adequate to carry out whether the IF condition satisfied or not. If all the rules were satisfied, the conduct occurred. If one or more of the rules were not satisfied the conduct did not occur.

- Legal rules can be tested with respect to fact by make use of two important logical connectives called

- AND-Here all the facts must be satisfied to reach the conclusion called for by the rule.

- OR-Here either fact can be satisfied to reach the conclusion called for by the rule

- Factor test requires the court to balance a list of several factors in determining whether to reach the conclusion called for by the rule.

Before going to define above factors following legal terminologies must be familiar in order to understand relation between all these factors when make use of these terms while conducting legal reasoning.

- Statute

- A statute is a formal, written endorsement passed by governmental body, whether federal, state, city, country with constitutional power to use legislative function in its jurisdiction.

- Guidelines defined the policy approved in a statute. "a rule usually derived from the law declared by concerned right of government[6].

- Case Law

- Case refers to actual or potential or hypothetical dispute which causes to question of whether any laws were violated or controversy which decided by the court [7]. 
Case may be civil or criminal etc... Judges make law by applying and interpreting the law whether common law or a statute on a case by case basis. Case law goes from a specific application to a general application.

- Legislature has the power to change the common law or enact common law rule into law by passing legislation. The court has no power to overrule or refuse to follow that statute unless it is invalid dated as unconstitutional. Although federal or state constitutions are more authoritative than a statute, the legislature cannot exceed its constitutional power.

- Court has the power to review a statute's validity. Although the constitutionality of a statute well generally arise in litigation when government attempts to enforce the statute against someone.

\section{Literature Study About Legal Reasoning}

The main motivation of authors behind this literature study is in order to know of the previous research done in this direction, the authors examined several studies dedicated to the topic Most of studies dealt with broader topics with references to most adequate information to build Legal expert system or Knowledge base system [KBS]. Although this section mainly covers various reasoning approaches in legal domain and dissimilar views of various authors models and ideas to build an expert system in desired area.

\subsection{Various Types of Legal Analysis Reasoning Approaches}

Following are the reasoning approaches usually make use of in legal reasoning process. a) Rule based analysis b) Precedent analysis or Analogy method c) Textual Reasoning \& Legislative Intent d) Policy Based Reasoning e) Tradition Reasoning

\section{1) Rule Based Analysis}

Rule base reasoning reaches an answer by establishing and applying a rule of law. It declares " $\mathrm{A}$ is the answer because the principle of law articulated by the governing authorities mandates it [8]. Rule based analysis can derive from a case or a statute. Break the rule into the separate elements to be established and then match the facts and circumstances of problem with each element of the rule to see if the element is proven.

a) Does this fact prove or disprove an element of the rule?

b) Does this particular circumstance prove or disprove an element of the rule?

\section{2) Precedent Analysis or Analogy Method}

Analogical reasoning reaches an answer by showing direct factual similarities between governing case law the clients' facts. It declares "R obtained as answer due to facts of this case are such as $\mathrm{X}$ vs. $\mathrm{Y}$ and $\mathrm{R}$ was the result there"[8].

When ever reasoning conducting by analogy, draw parallels between your factual situations and cases that have already been decided. Cases are made by their facts, so compare and contrast of facts and circumstances of case with decided cases. If key facts are similar, draw the analogy. If the key facts are varies then must apply a different rule. 
Reasoning by analogy is most often used in case analysis. Case analysis is a method used to predict the applicability of prior opinions to present controversy.

\section{3) Textual Reasoning \& Legislative Intent}

In this reasoning read and reread the statute and focus on its exact language. As in the rule based reasoning break the statute into separate elements to establish and then match the facts and circumstances of the problem with each element of the statute to see if the element is proven. Once the statute has been broken into elements, the statutory words must be understand and interpreted.

\section{4) Policy Based Reasoning}

Policy based reasoning achieved an answer by analyzing which answer would be the best for the society at large. It declares " $\mathrm{X}$ is the answer because that answer will encourage desirable results for our society and discourage undesirable results [8].

Policy arguments appeal to future consequences that follow from adopting a certain rule. The court first predicts the consequences that will flow from giving the law one interpretation or another then declares which set of consequences more consistent with underlying values of law [9]. Policy arguments are found both in case and statute but have few parameters.

\section{5) Tradition Reasoning}

Tradition reasoning achieved an answer by telling a story that calls forth that result. It declares " $\mathrm{X}$ is the answer because that is the way things have been always been done".

The U.S Supreme court has identified "tradition" as a principal test for determining our fundamental rights. Justice Scalia has authored "at least 53 opinions that relied expressly on tradition to resolve constitutional issues [10].

\subsection{Earlier Authors Views in Legal Reasoning Areas}

HYPO system [11] that applies case-based reasoning in the legal domain using a 6 stage process. HYPO use of CBR (case based reasoning) has the considerable advantage for the legal domain of outputting alternative arguments as opposed to definitive answers. This provides a more realistic outcome which is more reflective of the open-textured nature of legal problem solving. HYPO system has been utilized in a more recent system known as CATO [12] to teach law students how to reason with case law precedents in the law relating to trade secrets and confidential commercial information.

$\boldsymbol{A S H D - I I ~ [ 1 3 ] ~ w a s ~ d e v e l o p e d ~ a s ~ a ~ h y b r i d ~ l e g a l ~ s y s t e m ~ i n ~ t h e ~ a r e a ~ o f ~ d i v o r c e ~ l a w . ~ I t ~ c o n s i s t e d ~ o f ~ a ~}$ rule base and a case base. The reason for the development of this hybrid was to take advantage of both of these methods since the nature of law means that it can be necessary to use precedents (easily represented by CBR) and other legal sources such as statutes, codes (more easily represented in a rule based format). The system illustrated that there was success in terms of creating the hybrid system but that even this did not did not fully capture the behavior of a legal practitioner and they concluded that the system was more useful as an aid to the less experienced practitioner.

ZombAIs[14]: This System emphasizing about likelihood ways of computer assistance in order to deduce resolves and proofs.although it is developing software to show if the "artificial brains" build in Artificial Intelligence using expert system methodology. This research would become the 
next generation control system "beyond the grave". In the primary step, they developed a method of challenges about analysis encountered by legal rules in order to interpret automatically using AI techniques.

WINCAAS [15] is a rule based system which is in commercial use. Credit law was an appropriate domain since it is not particularly beset by strongly open textured predicates. Further the users of the expert system are lawyers who can interpret open texture in the same way as they might interpret open texture found in a book or piece of legislation. Under these conditions we believe that rule based systems can be genuinely useful.

HILDA [16] (Hybrid Integrated Legal Decision Assistant) uses certain features of legislation and cases to implement some aspects of the patchy domain theory present in an area of law. This allows HILDA to engage in rule based reasoning ("RBR) and CBR both with and without refinement and modification of the patchy domain theory by a neural network.

OWL Ontology and Bayesian Network Model [17] describes the development of a legal decision support guide for owner's corporation cases in the state of Victoria, Australia that uses an OWL ontology and Bayesian Network to perform legal reasoning. As increasing population there must be adequate to manage by the government in this concern legal reasoning most essential. Regarding few Cases which could not be taken any by negotiate with civil judgement..By using this expert system model analytically all legal rules and associated out comes results. These conclusions based on precedent cases and web based information extraction about decision. Apart from this consistent reasoning conducted using Bayesian Belief network. This model assists to take decision against to compliance which is helpful to the owners of the corporation.

Default-Logic Framework [18] is the model which uses combined rule based and case base reasoning as a hybrid model in legal domains. This framework used by the Decision Apprentice Software to conclude legal decisions.

A Fuzzy Legal Inference System [19] this system uses case base reasoning to perform legal decisions. Although main issues and characteristics cases determined based on the fact patterns and statute rules. Fuzziness is represented by membership functions. Features and case rules, written in terms of frame, are stored in a case base. Cases similar to a new case are retrieved by issues and features; inference is made by case rules.

\section{Conclusions}

In this paper we have identified and discussed the importance of research information which is most adequate for further research in a desired area of legal domain. Although the views expressed to build a legal expert system to provide a service and take right decision by the people while acquiring immovable property according Indian legal system. Apart from various approaches or models to conduct legal reasoning has been identified using AI Techniques.

The future scope of this research work is applicable in many aspects of legal situations where intelligent decision making is needed rather than depends on human expert. Ultimately legal expert system may useful to the user as decision maker or service provider in a specific domain. 


\section{REFERENCES}

[1] Jackson, Peter (1998), Introduction to Expert Systems (3 ed.), Addison Wesley, p. 2, ISBN 978-0201-87686-4.

[2] Cornelius T. Leondes (2002). Expert systems: the technology of knowledge management and decision making for the 21st century. pp. 1-22, ISBN 978-0-12-443880-4.

[3] Luger \& Stubblefield 2004, pp. 227-331.

[4] Feigenbaum, E. A. 1982. Forward. In Davis, R., and Lenat, D. B., eds.Knowledge-Based Systems in Artificial Intelligence. McGraw-Hill.

[5] Feigenbaum Edward A McCorduck Pamela [1983], 5th generation, First Edition, ISBN 978-0-20111519-2, and OCLC 9324691.

[6] Black's Law Dictionary 228 (7th ed. 2004).

[7] Black's Law Dictionary 1286 (8th ed.2004).

[8] Linda Holdman Edwards, Legal writing: Process, Analysis, and Organization, at 5, (1996)

[9] Wilson Huhn, 5 Types of Legal Argument, 60, 2002.

[10] Rebecca L.Brown, Tradition and Insight (1993), 103 Yale L.J. 177, 179-180

[11] Rissland E. Ashley, K, Branting, K. 2006, Case Based Reasoning \& Law, The Knowledge Engineering Review, vol. 20:3, 293-2981.

[12] Aleven, V., 1997, Teaching case-based argumentation through a model and examples, PhD thesis, University of Pittsburgh

[13] Pal, K., \& Campbell, J., 1997, "An Application of Rule-Based and Case-Based Reasoning With in a Single Legal Knowledge-Based System”, The Data Base for Advances in Information Systems, vol. $28,4$.

[14] Burkhard Schafer, Legal Expert Systems as Representatives (1993) Augst "Beyond the Grave", Volume 7, Issue 2.

[15] Vossos, G., Zeleznikow, J., Moore, A. and Hunter, D. (1993). The Credit Act Advisory System CAAS): Conversion from an expert system prototype to a $\mathrm{C}++$ commercial system. In the Proceedings of the Fourth International Conference of Intelligence \& Law. ACM Press. Pp 180-183.

[16] Peter A. Egri (1995) "Knowledge Extraction from Neural Networks in Legal Rule Based and Case Based Reasoning”, IEEE- 0-7803-2768-3.

[17] Peter Condliffe, Brooke Abrahams and John Zeleznikow,(2010) "An OWL Ontology and Bayesian Network to Support Legal Reasoning in the Owners Corporation Domain".

[18] Vern R. Walker, (2006) “A Default-Logic Framework for Legal Reasoning in Multi Agent Systems”, in Technical Report FS-06-05 for the 2006 Fall Symposium of the American Association for Artificial Intelligence.

[19] Kaoru Hirota, Hajime Yoshino Ming Qiang Xu Yan Zhu, Xiao Yi Li, Daigo Horie (1998) “A Fuzzy Case Based Reasoning System for legal inference”, 0-7803-4863-X/98 - IEEE.

\section{Authors}

1. M.Venkateswarlu Naik working as a CSE faculty in KMIT, Hyderabad. He has Published various National Conference and International Journals. He is an ISTE Member. He is working as resource person in various organizations. His interesting domain areas are Artificial Intelligence, Expert System, Natural Language Process, Information Retrieval System.

2. Sushant Lokhanday working as a CSE faculty in KMIT, Hyderabad. He worked In real time industry on various technologies. He worked as SAP Consultant in Software industry. His interesting domain areas are Artificial Intelligence, Grid Computing, Cloud Computing, Ex pert System, Natural Language Process, Information Retrieval System.
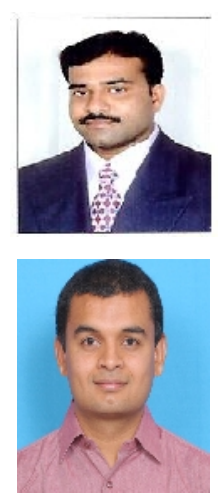
International Journal of Computer Science \& Information Technology (IJCSIT) Vol 4, No 5, October 2012

Table 1. Various Expert Systems in distinguish domains

\begin{tabular}{|c|c|c|}
\hline $\begin{array}{l}\text { Expert } \\
\text { Systems }\end{array}$ & $\begin{array}{l}\text { Name Expert } \\
\text { System }\end{array}$ & Purpose \\
\hline \multirow{2}{*}{ Chemistry } & CRYSALIS & Interpret a protein's 3-D structure \\
\hline & DENDRAL & Interpret Molecular structure \\
\hline \multirow{2}{*}{ Medical } & PUFF & Diagnose lung disease \\
\hline & COAG & Diagnose blood disease \\
\hline \multirow{2}{*}{ Electronics } & $\mathrm{ACE}$ & Diagnose telephone network faults \\
\hline & PALLADIO & Design \& test new VLSI circuits \\
\hline \multirow[b]{2}{*}{$\begin{array}{l}\text { Engineerin } \\
\mathbf{g}\end{array}$} & REACTOR & Diagnose reactor accidents \\
\hline & STEAMER & $\begin{array}{l}\text { Instruct operation of steam power } \\
\text { plant }\end{array}$ \\
\hline \multirow[b]{2}{*}{ Geology } & MUD & Diagnose drilling problems \\
\hline & PROSPECTOR & $\begin{array}{l}\text { Interpret geological data for } \\
\text { minerals }\end{array}$ \\
\hline \multirow[b]{2}{*}{ Computer } & BDS & Diagnose bad parts in switching net \\
\hline & XSEL & $\begin{array}{c}\text { Configure DEC computer sales } \\
\text { order }\end{array}$ \\
\hline \multirow{2}{*}{ Legal } & ASHD & Divorce Law \\
\hline & HYPO & Legal Reasoning \\
\hline
\end{tabular}

